\title{
A Low Cost Course Information Syndication System
}

\author{
A.O. Ajayi, E.A. Olajubu, S.A. Bello, H.A. Soriyan, \\ and A.V. Obamuyide \\ Obafemi Awolowo University, Ile-Ife, Nigeria
}

\author{
anuajyi@oauife.edu.ng; emmolajubu@oauife.edu.ng; \\ sbello@oauife.edu.ng; hsoriyan@oauife.edu.ng; \\ obabiola@gmail.com
}

\section{Executive Summary}

This study presents a cost effective, reliable, and convenient mobile web-based system to facilitate the dissemination of course information to students, to support interaction that goes beyond the classroom. The system employed the Really Simple Syndication (RSS) technology and was developed using Rapid Application Development (RAD) methodology. The design of the system was modeled using Unified Modeling Language (UML) diagrams, while its implementation was done using Java Micro Edition (JME) and "PHP: Hypertext Preprocessor" (PHP).

A simulation technique was used to evaluate the proposed system performance by comparing the approach used in its design to one adopted in a similar study, using response time and bandwidth consumption as metrics. The results obtained revealed that the performance of the proposed syndication system was better. Similarly, an experiment to investigate the students' perception of the system was conducted, with students' responses revealing a tremendous success of this project.

Keywords: Mobile phones, Learning environment, Education, Time management, Bandwidth.

\section{Introduction}

Decades ago, educators, school administrators, and students in higher learning used wired technology to help in teaching and learning. In this century, however, institutions of higher learning are moving towards the use of mobile wireless technologies to improve efficiency because of the inflexibility associated with the wired technology (Correia, Faria, \& Assuncao, 2001). This movement to mobile wireless technologies is now the common technology in higher education (McKenzie, 2001, Oliver, 2005), as there are an increasing number of institutions offering courses using mobile wireless technologies as alternative teaching and learning tools (Dvorak \& Burchanan, 2002; Jones, Jo, \& Cranitch, 2002). Besides, initial studies done on the usage of mobile technology have shown the useful-

Material published as part of this publication, either on-line or in print, is copyrighted by the Informing Science Institute. Permission to make digital or paper copy of part or all of these works for personal or classroom use is granted without fee provided that the copies are not made or distributed for profit or commercial advantage AND that copies 1) bear this notice in full and 2) give the full citation on the first page. It is permissible to abstract these works so long as credit is given. To copy in all other cases or to republish or to post on a server or to redistribute to lists requires specific permission and payment of a fee. Contact Publisher@InformingScience.org to request redistribution permission. ness of mobile technology in education (Virvou \& Alepis, 2005). Mobile learning is any form of learning and teaching that occurs through a mobile device or in a mobile environment (Nyiri, 2002). The most obvious application of mobile devices in education is on the cognitive and pedagogical aspects (Dvorak \& Burchanan, 2002; Jones et al., 2002; Virtanen, John, \& Wright, 2002; Way- 
cott, 2002). Using mobile technology to interact with students comes with many benefits, which include increased performance and improved productivity.

Regardless of the fact that mobile wireless technologies provide many benefits, there is very limited research on the use of mobile wireless technology in educational system in developing countries compared to, for example, Europe (Smørdal, Gregory, \& Langseth, 2002) and America (Virtanen et al., 2002). In many universities in Nigeria, for instance, the prevalent means of passing vital information to students is through the traditional classroom method, which involves the direct interaction (physical contact) of faculty with students anytime information is to be disseminated. Additionally, information requiring students' attention is placed on the doors of lecturers' offices or on discreetly located notice boards. These methods of information dissemination have proved to be ineffective as evidenced in the numerous instances of students reporting missing tests, assignments deadline, or, worse, examination. Again, most students do not have a reliable means of keeping abreast of happenings in their course of studies, and most times, they often rely on verbal communication, which is not always reliable. This serves to diminish the effectiveness and efficiency of lecturers and students.

Consequently, there is the need for a reliable and convenient system for students-lecturers interaction that goes beyond the classroom, which lecturers and students can use to keep themselves informed of latest developments. In this study, we develop a mobile web-based system to facilitate the dissemination of course information in a more reliable and convenient form, by employing the Really Simple Syndication (RSS) technology, an Extensible Markup Language (XML) based web standard, to publish frequently updated digital content to users. Lecturers and students can use this system to get updates (blogs, wikis, news, announcements, and so on) from many websites that are relevant to their studies by simply using RSS technology to track new developments on these websites, thus bringing efficiency in the use of time. RSS has become an essential web publishing vehicle due to its simple and easy-to-use interface (Asmus, Bonner, Esterhay, Lechner, \& Rentfrow, 2005). Again, in terms of security, RSS is better than email list subscription, as it does not require users to give their email addresses or phone numbers. Moreover, instead of visiting each student's individual blog, lecturers can subscribe to an RSS feed of their students' blogs to obtain instant notifications and updates relating to new contents added by students. This will dramatically reduce lecturer's workload. Similarly, students can subscribe to the feeds of their friends, peers, and lecturers. Developing such a system will help keep students up to date about course resources, assignments, their due dates, tests announcements, and even sending or reading materials. This in the long run will improve their learning, satisfaction, and pass rates.

The domain of mobile learning includes wide variety of applications with new teaching and learning techniques. Discussion on related studies on the use of mobile devices as educational supporting tools follows.

Stone and Briggs (2002) conducted an experiment to validate the effectiveness of a two-way SMS campaign in a university environment. The experiment revealed that students preferred SMS as a medium of communication to e-mail or web-based announcements due to its convenience. Lehner, Nosekabel, and Lehmann (2002) reported a Campus-Mobile Project at the Berlin University, where students use mobile wireless phones to send and receive SMS through WAP. Customized information, based on student's profile and created from different sources and formats, is transmitted to the students' WAP phone displays to do research and class work.

At the University of Helsinki, the "Learning In Virtual Environment" (LIVE) experiment was conducted using SMS with WAP phones (Seppälä, 2002) to specifically introduce digital imaging and photo sharing between lecturers, thereby introducing the possibility of using Multimedia Messaging Service (MMS) and other 3G services in m-learning. Collett and Stead (2002) developed M-learning materials for people with literacy problem and concluded that the technology 
had great impact on students' interest in the subject studied. Garner, Francis, and Wales (2002) developed an SMS based system and conducted an experiment to evaluate SMS use in supporting undergraduate students at the Sheffield Hallam University. The findings obtained were overwhelmingly positive, with students perceiving the system to be immediate, convenient, and personal. Tong, Hu, Han, and Yang (2005) developed a mobile learning platform to support multimedia courses delivery, specifically an assistant system to solve the learning status monitoring issue. Similarly, Corlett, Sharples, Bull, and Chan (2005) developed and evaluated a mobile learning organizer to provide timetabling information and course content for university students.

Glotzbach, Mordkovich, and Radwan (2008) used a similar idea to the one used in this study: in the context of using RSS technology for a course announcement system at the Purdue University. Key results included the students' willingness to accept the technology and the variety of learning modules. However, their RSS feed implementation allowed the students to keep track of course announcements made by the course professor; it did not allow students to post and receive important course announcements from their peers. Our proposed tool allowed lecturers to post announcements as well as students to post and receive course announcements to their peers using mobile wireless phones. Ismail and Idrus (2009) developed a framework to improve distance learners' education at the Universiti Sains Malaysia, using SMS mobile technology for a physics course. The comments by the students reflected a tremendous success of this project.

However, many of the systems described above require the use of smart and WAP phones, which are very expensive, and SMS based systems, which are similarly costly. Many users in developing countries prefer affordable and low-cost mobile devices with low user charges to expensive ones. Surfing the Internet in Nigeria is cheaper when compared to SMS, depending on the mobile telecommunication network operator the user is subscribed to. Internet browsing on the MTN Nigeria network for instance, costs $\$ 0.67 /$ day compared to $\$ 0.10 /$ message, the cost of sending a message using SMS. Government owned universities in Nigeria do exhibit issues in their student enrollments. For illustration purposes, we will assume an average class size of 70 . If we assume that vital course information is to be disseminated to students using the SMS technology and the information syndication system being proposed in this study, it will cost $\$ 7.00$ (i.e., sending a message to each student at the rate of $\$ 0.10$ /message) compared to $\$ 0.67 /$ day, which is the cost of Internet access when the proposed information syndication system is used. Similarly, if we assume that two important course announcements are to be given on a typical day to students, it will cost $\$ 14.00$ using the SMS technology, while it is only $\$ 0.67$ for the proposed technology. Thus, this cost will exponentially increase depending on the class size and the number of course announcements to be made. Truly, as revealed in Gillard, Bailey, and Nolan (2008), IT educators are always looking for a breakthrough in technology that will increase classroom productivity, but they are often deterred by the system development time or by the cost of such a technology. This study discusses a low cost solution that has a minimal development time to enhance collaboration and productivity in a classroom setting.

Besides, many web applications require much bandwidth, which is a major communication challenge in developing countries. In addition, limited bandwidth is an important factor in wireless connections when compared to the wired ones, in that communication conditions change dynamically due to the fading effects in wireless communication. This greatly degrades multimedia quality in handheld devices. This study aims to address some of these deficiencies by implementing a cost effective notification system by making use of cheaper phones to expensive smart phones and about $70 \%$ of the application data in the system limited to text to address the limited bandwidth problem and the small screen size of mobile phones.

The goal of the paper is to develop a low cost effective course information syndication tool based on the RSS technology for course information exchange between students to students and faculty to students and to measure the students' perception of the tool in facilitating collaboration and 
enhancing their learning. The paper begins with introductory remarks that include the usage of mobile wireless technologies in higher education, the purpose of the paper, and a review of the literature on the use of mobile devices as educational supporting tools. Next, the proposed course information syndicate system model and its implementation are presented. Subsequently, the performance evaluation and the student's perception of the system are presented. Conclusion and recommendations complete the paper.

\section{Method}

\section{Proposed System Design}

The architecture of a system, which allows lecturers to syndicate news items about courses they teach to students easily using mobile technology, is shown in Figure 1. The design of such a system is achieved by developing a web-based interface that lecturers can use to push out information and a mobile reader that displays such information to students. The interface is designed such that it can easily be integrated to any course website. The web module functions as an RSS generator that generate, update, and edit RSS feeds stored on the web server that hosts the course website. Feeds are documents used to transfer frequently updated digital content to users. The mobile application will on every start up contact the course web server to retrieve latest contents, which are then displayed to students.

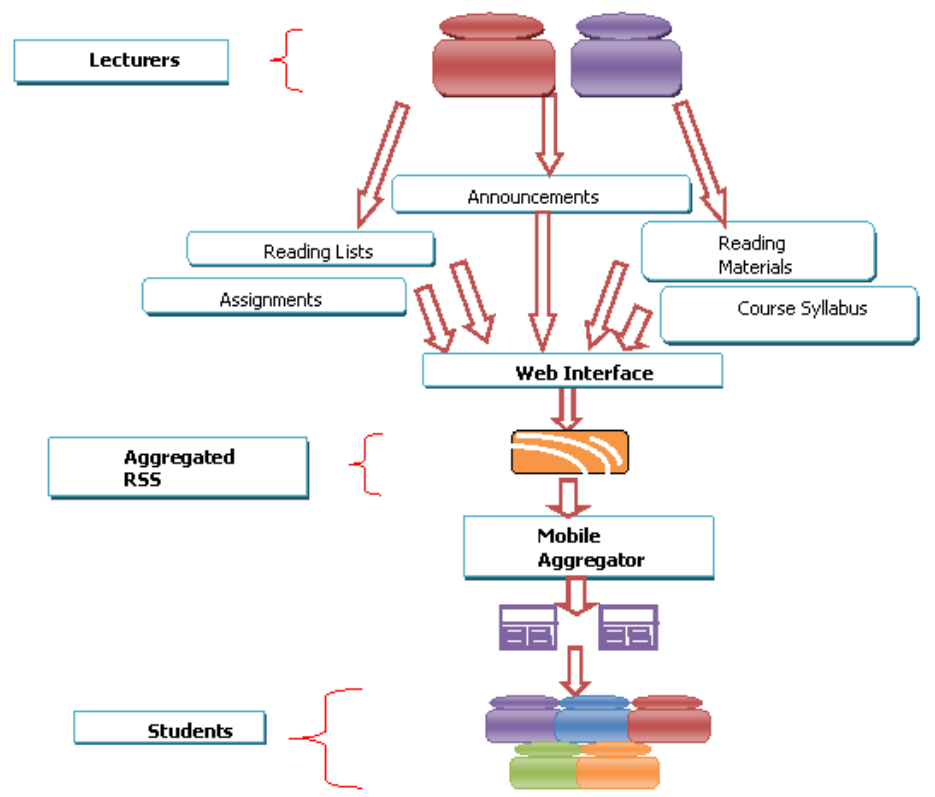

Figure 1: Architecture of the syndicate system

The system was developed using Rapid Application Development (RAD) methodology, because it strongly embraces object-oriented programming, fosters software reuse, small team structure, and distributed system development. The Unified Modeling Language (UML) diagrams used to model this system include class diagram and use case diagram.

The mobile application module consisted of four classes, namely, RssFeed, RssItem, RssParser and Settings. RssItem class is used to create objects representing news items in RssFeed. Class RssFeed is used to instantiate a single RSS feed, RssParser class is used to parse feeds, while class Settings is used to manage user preferences. The attributes of an RssFeed are its name, its uniform resource locator, and the news items that make up the feed, while an RssItem class has title, link, and description as attributes. The class RssParser uses the Kxml xml parsing library, 
while class Settings uses Mobile Information Device Profile (MIDP)'s Record Management Store (RMS) to store user preferences. The class diagram depicted in Figure 2 shows the relationship between the four classes described earlier and the RssReaderMidlet class. Figure 2 also indicates a one-to-many relationship between RssFeed and RssReaderMidlet classes. Figure 3 shows the relationship among the various classes in the web module component.

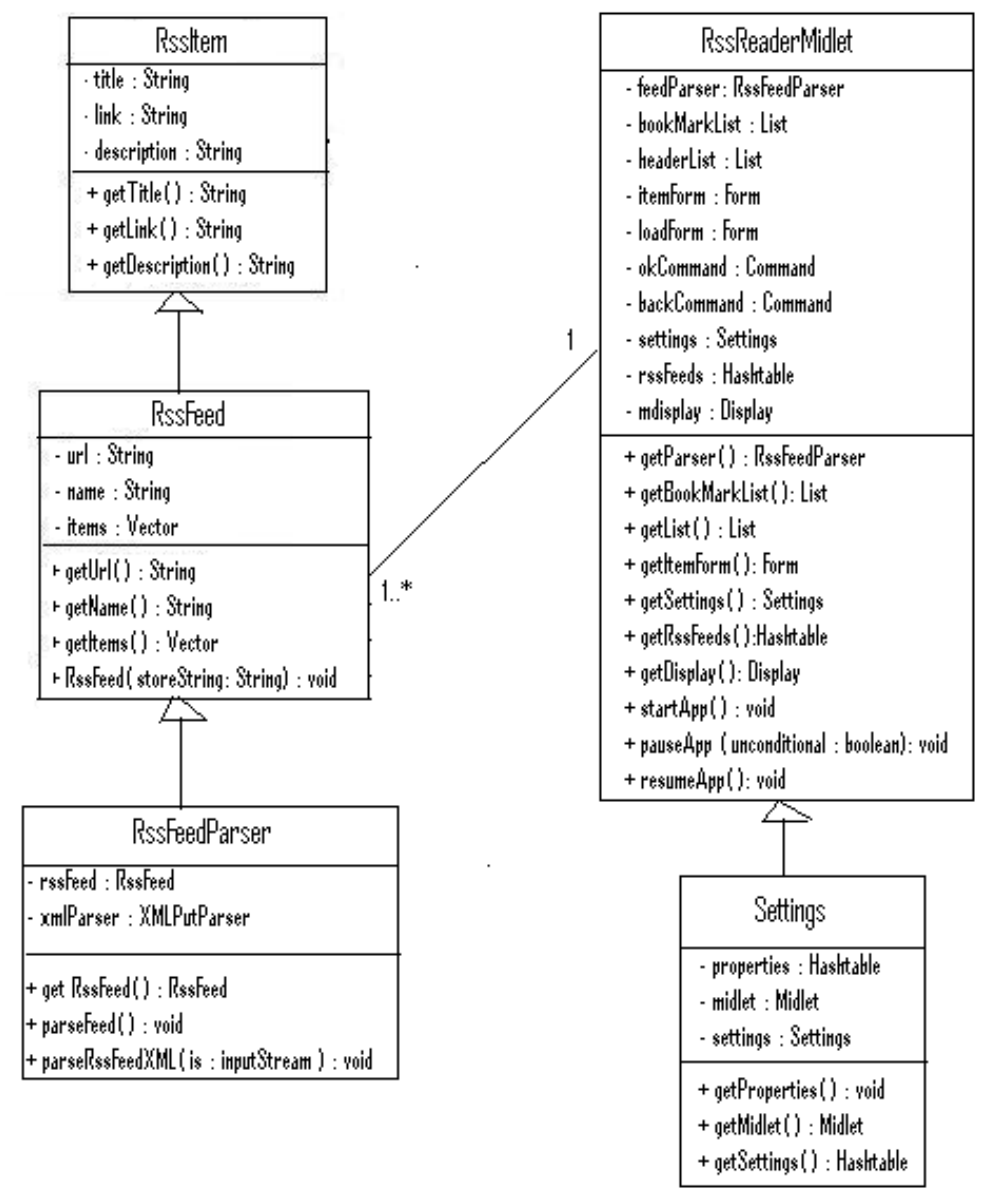

Figure 2: Classes in the mobile application module

Figure 4 illustrates the use case scenario of a student interacting with the system. Through mobile application, the student can add feeds, edit feeds, view feeds, and delete feeds. To add feeds, for example, a student needs to enter only the feed title and its web address, and the mobile application bookmarks the feed and automatically updates the student with the new contents available from the feed. The same principle applies for a lecturer interacting with the system, but in addition to editing feeds, viewing feeds, and deleting feeds, a lecturer can also publish feeds.

\section{Implementation}

The system consists of two modules- mobile client and RSS authoring web modules. The mobile client is a Java Mobile Edition application built on top of the MIDP, making it capable of running on most Java powered phones. The two major languages used to implement the system are Java Mobile Edition (JME) and PHP: Hypertext Preprocessor (PHP). The primary Midlet for the Mobile client module was designed using Visual Mobile designer available in Netbeans. The data transport for the mobile software was implemented using basic HTTP 1.0, to allow phones with the basic General Packet Radio Service (GPRS) connectivity to work with the system. 
The web module was designed using Adobe Dreamweaver and tested with WAMP (Windows, Apache, MySQL and PHP) server software.

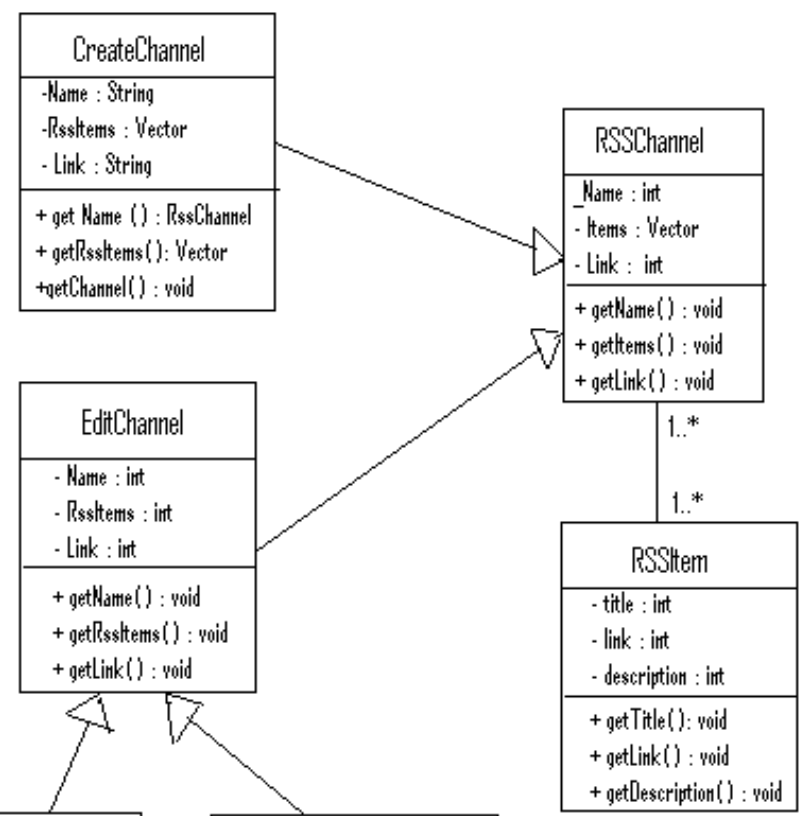

\begin{tabular}{|c|}
\hline Indatéthamel \\
\hline 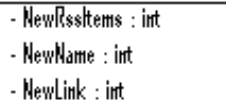 \\
\hline 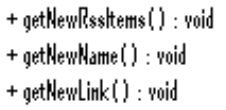 \\
\hline
\end{tabular}

\begin{tabular}{|c|}
\hline 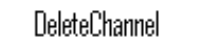 \\
\hline $\begin{array}{l}\text { - Chanthenduttre : int } \\
\text { - Link : int }\end{array}$ \\
\hline 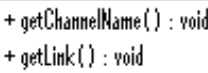 \\
\hline
\end{tabular}

Figure 3: Classes of the web module

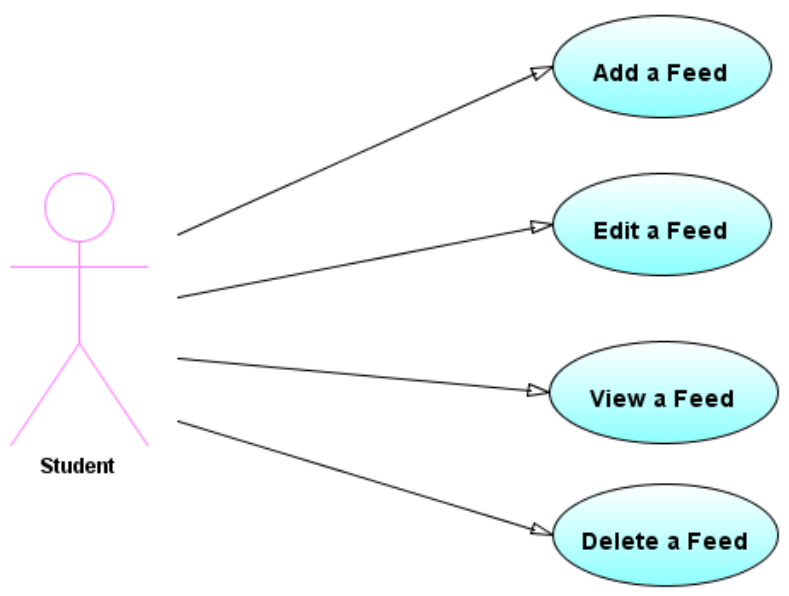

Figure 4: Use case scenario of student's interaction with the system 
Figure 5 depicts the interface shown during a typical installation of the web module, and, for security reasons, a user must specify both username and password to proceed with the installation. After the installation, the user sees the screen depicted in Figure 6, to begin feeds publishing. To publish a feed, say for a course (CSC 401), the lecturer enters the URL of the feed to create (see Figure 7), followed by the number of items in the feed (Figure 8), and then the full channel address of the course web site. Figure 9 depicts the real implementation of the system, having items displayed on the feed. The user interface features an editor used to edit feed items and channels, thus the lecturer can create course information content (course syllabus, lectures, assignments, tutorials, labs, and useful links) using the interface.

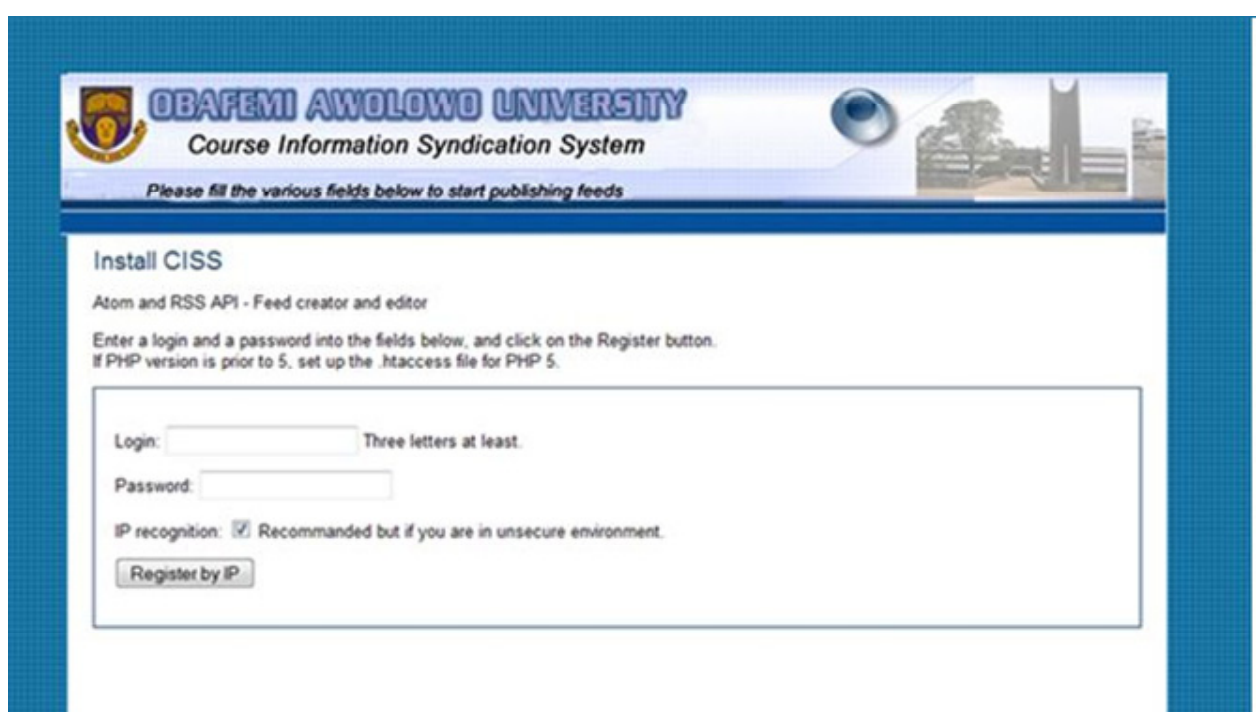

Figure 5: Login page of the web

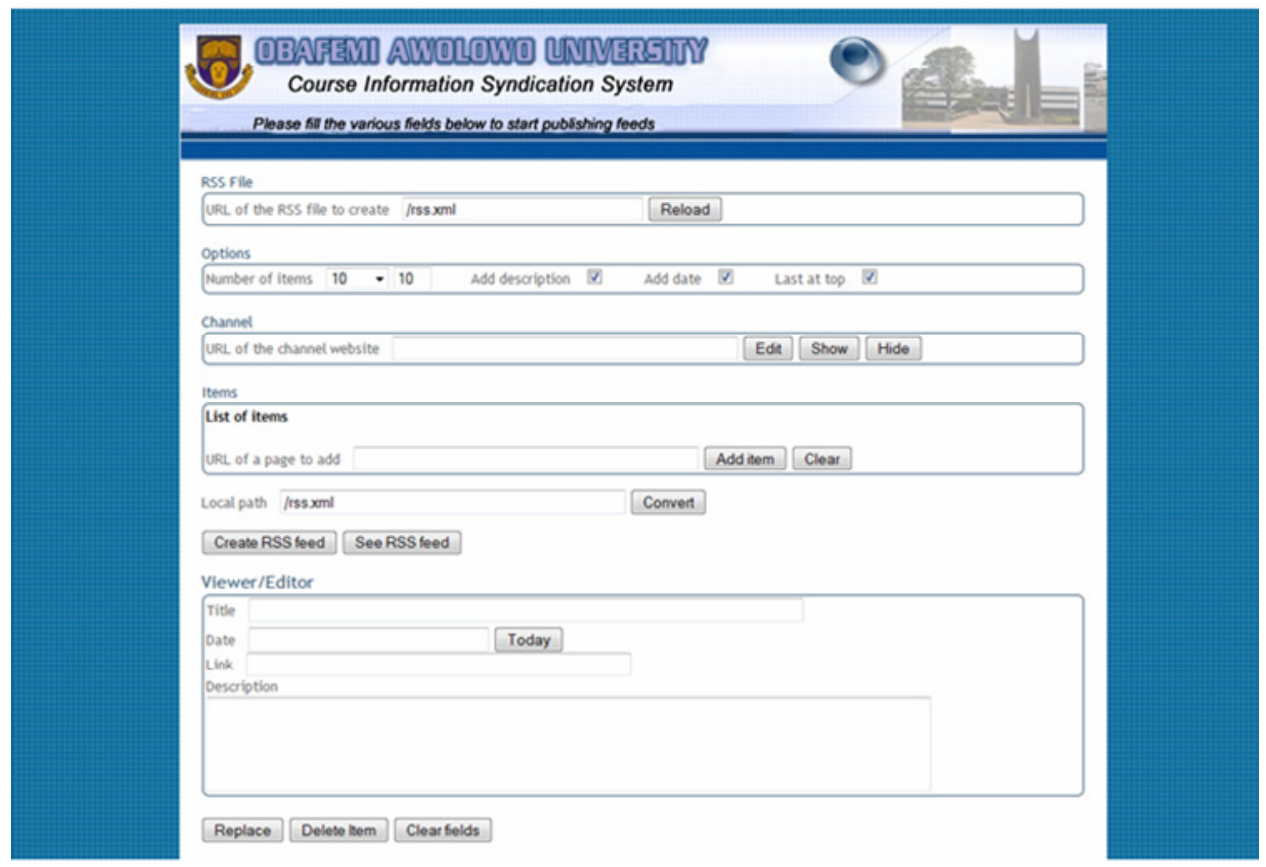

Figure 6: Interface for the web module 


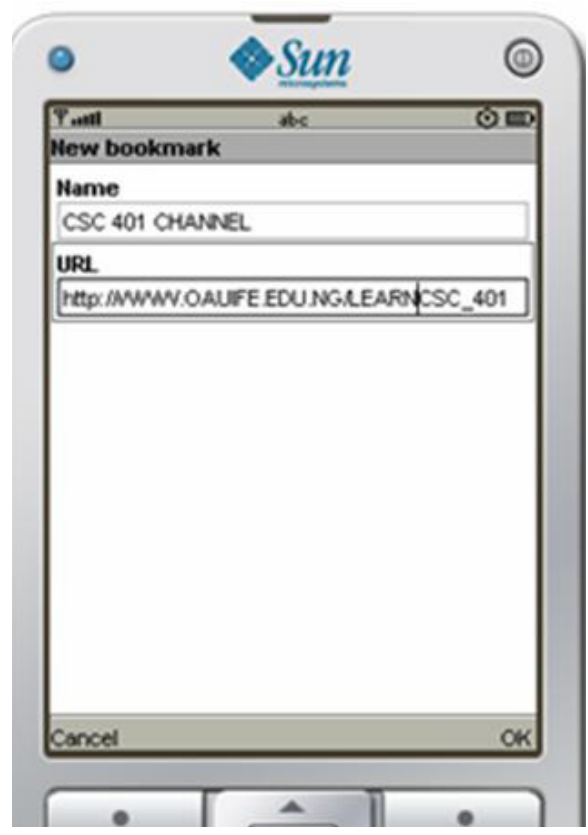

Figure 7: Interface for adding a feed

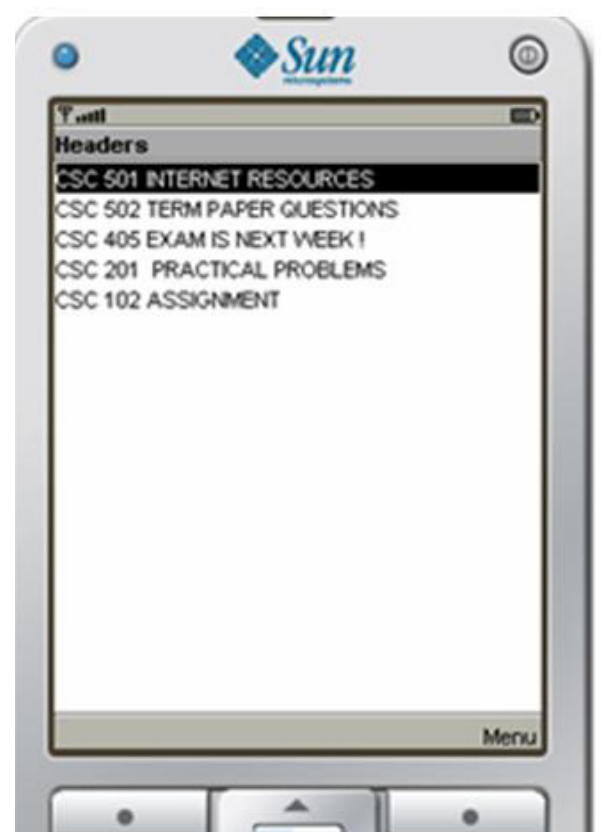

Figure 8: A feed being displayed

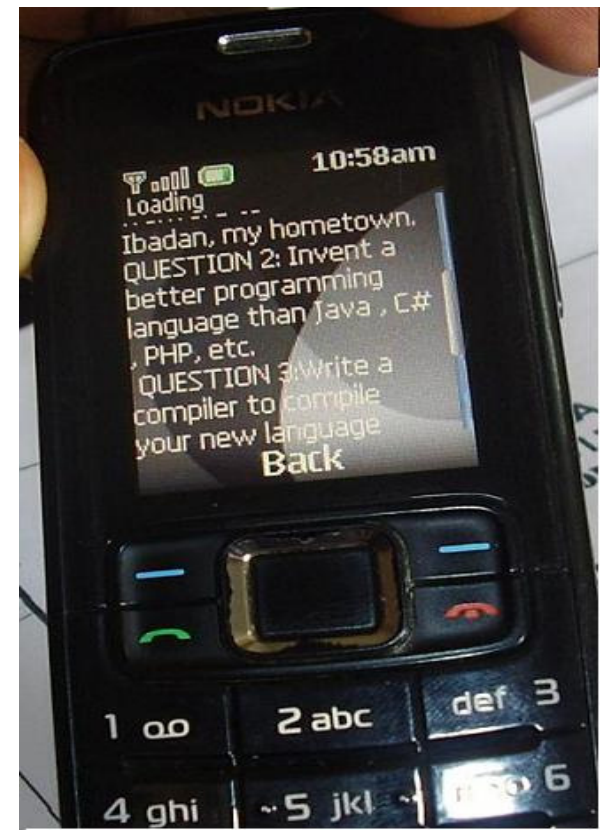

Figure 9: Real life implementation of the tool

\section{Performance Evaluation}

The purpose of a simulation technique to evaluate a system is to justify its design. This is done by comparing the approach used in its design to others used in a similar study. The proposed system uses the basic HTTP 1.0 for communication between mobile and web modules; we, thus, compare this HTTP-based approach with wireless application protocol (WAP) approach used in 
(Glotzbach et al., 2008). The purpose is to justify the strengths of the approach used in the design of our system, using response time and bandwidth consumption as metrics. Additionally, the user experience that a web application offers is an integral component of that application's overall reliability. If users of an Internet-based application experience certain difficulties or perceived the performance of the application as poor, for example, because of high response time, they will not consider the services of the application as dependable. Response time and bandwidth were used as performance metrics because they are the two most important performance metrics for wireless and mobile network applications. Besides, there is a relationship between the two metrics in that there is usually an increase in user-perceived response time as bandwidth utilization increases (Ajayi, Aderounmu, Soriyan \& Amos, 2010). It is therefore in the best interest of a web application designer to provide a consistent user experience at all times. Because the proposed course information syndication system conducts interactions with the students through the Internet, we give an indication of the end-user experience under normal and adverse conditions (high demand) in this section.

Response time is the amount of time required for information requested from the system to get to the user and is simply the elapsed time between when a request is made and the time a response to that request arrives. Assuming a fixed and hypothetical bandwidth, $B W$, then the relation of response time $(R T)$ for WAP and HTTP respectively are:

$$
\begin{gathered}
R T_{h t p p}=\frac{r q+r p}{B W} \\
R T_{W A P}=\frac{r q+r p+f}{B W}
\end{gathered}
$$

Where $r q$ is the request size (in kilobyte), $r p$ is the response size (in kilobyte) and $f$ is the formatting information size (in kilobyte). Let the total request-response size, TRR (in kilobyte) $=r q+$ $r p$, then we can rewrite (1) and (2) generally as:

$$
\begin{array}{r}
R T_{h t p}=\frac{T R R}{B W} \\
R T_{W A P}=\frac{T R R+f}{B W} \\
R T_{W A P}=\frac{T R R}{B W}+\frac{f}{B W}
\end{array}
$$

which gives

$$
R T_{W A P}=R T_{h t p}+\frac{f}{B W}
$$

Since $\frac{T R R}{B W}$ is the same for both WAP and HTTP, thus for any request, $R T_{h t p}<R T_{W A P}$ because $R T_{W A P}$ increases as $f$ increases. This relationship is shown in Figure 10, given $B W$ as $12 \mathrm{kbps}$.

Bandwidth consumption is the amount of data sent through a transmitting medium (computer network) in a given amount of time. If the transmission time, say for a request, $r q$ is $t r q$, and the transmission time for a response $r p$ is trp, then the bandwidth requirement for HTTP is:

$$
\text { Bandwidth }_{h t p}=\frac{r q+r p}{\operatorname{trq}+\operatorname{trp}}
$$

while that for WAP is:

$$
\text { Bandwidth }_{W A P}=\frac{r q+r p}{t r q+t r p}+B f
$$

That is, 


$$
\begin{array}{r}
\text { Bandwidth }_{\text {htp }}=\frac{T R R}{T R R_{t}} \\
\text { Bandwidth }_{\text {WAP }}=\frac{T R R}{T R R_{t}}+B f \\
\text { Bandwidth }_{\text {WAP }}=\text { Bandwidth }_{\text {http }}+B f
\end{array}
$$

where $T R R$ is request- response size (in kilobyte), $T R R_{t}$ is the total transmission time for $T R R$ in seconds, and $B f$ is the additional bandwidth required to format information $f$. Bandwidth ${ }_{\mathrm{WAP}}$ increases as $B f$ increases. Thus, for any request, Bandwidth $h_{h t p}<=B a n d w i d t h_{W A P}$. This is depicted in Figure 11 by varying $T R R / T R R_{t}$ between $0-12 \mathrm{kbps}$ and randomly generating values for $B f$.

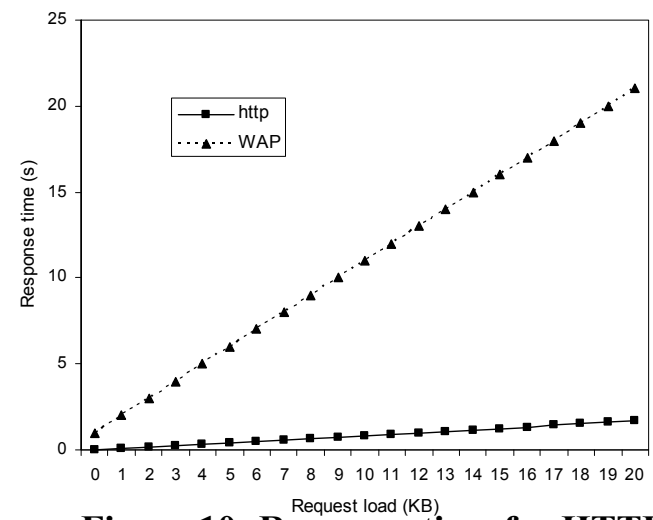

Figure 10: Response time for HTTP and WAP

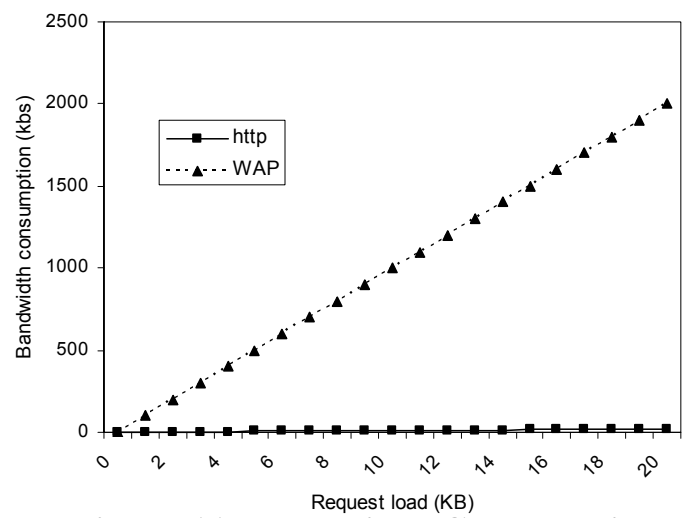

Figure 11: Bandwidth Consumption for HTTP and WAP

\section{Students' Perception of the Tool}

The application of the system prototype to a computer graphics (CSC 514) course offered in Rain Semester, 2008/2009 Session at the Obafemi Awolowo University, Ile-Ife, resulted in an improvement of student progression and satisfaction rates.

Data was collected using questionnaires, where students were asked to evaluate the tool in order to obtain their feedback on how the tool was able to manage their schedules and facilitate the learning of computer graphics. The questions were designed in a way to capture many aspects of teaching and learning processes, an efficient notification system in a computer graphics course, and the delivery mechanisms involved.

Forty students (40) out of forty-five (45) originally sampled, participated in the survey, giving a return rate of $89 \%$, and a 5-point Likert scale (from 1 - strongly disagree, to 5 - strongly agree) was applied to a set of questions (12 in all) related to their satisfaction with various aspects of the course.

Comments given by the respondents seem to indicate that the tool appealed to the students (see Table1). The majority of the students gave their highest scores to two of the questions regarding the cost of using the technology and its ease of use. The majority of the students (75\%) had the perception that the tool is user friendly and easy to use, while (77.5\%) strongly disagreed that the tool is costly.

In terms of personal information management, the students agreed that the tool was effective for time management especially, since it reminds them of tutorials, assignment, and deadlines. It also allows them to schedule their workload and assign time for specific modules to maximize effectiveness of their studies. Thus, confirming the results obtained in Kim, Mims, and Holmes (2006) 
that mobile wireless technologies can help improve efficiency and effectiveness in teaching and learning.

The students' responses revealed a tremendous success of this project. In fact, the students advised that this technology be introduced to other courses in the department.

Table 1: Student questionnaire with numerical responses

The objective of this questionnaire is to measure students' interest and perception of the Information Syndication Tool as well as its effectiveness in adding value to the process of knowledge acquisition. Please rate how strongly you agree or disagree with each of the following statements by placing a check mark in the appropriate box.

\begin{tabular}{|c|c|c|c|c|c|c|c|}
\hline S/no & Question & $\begin{array}{l}\text { Strongly } \\
\text { Disagree }\end{array}$ & Disagree & $\begin{array}{l}\text { Unde- } \\
\text { cided }\end{array}$ & Agree & $\begin{array}{l}\text { Strongly } \\
\text { Agree }\end{array}$ & $\begin{array}{l}\text { Response } \\
\text { Average }\end{array}$ \\
\hline 1 & $\begin{array}{l}\text { I am proficient in web brows- } \\
\text { ing and mobile technology } \\
\text { usage }\end{array}$ & $0.0 \%(0)$ & $5.0 \%(2)$ & $5.0 \%(2)$ & $27.5 \%(11)$ & $\begin{array}{l}62.5 \% \\
(25)\end{array}$ & 4.48 \\
\hline 2 & I use the tool regularly & $5.0 \%(2)$ & $7.5 \%(3)$ & $2.5 \%(1)$ & $37.5 \%(15)$ & $\begin{array}{l}47.5 \% \\
(19)\end{array}$ & 4.15 \\
\hline 3 & $\begin{array}{l}\text { I had difficulty using this tool } \\
\text { for this course }\end{array}$ & $7.5 \%(3)$ & $10.0 \%(4)$ & $2.5 \%(1)$ & $47.5 \%(19)$ & $\begin{array}{l}32.5 \% \\
(13)\end{array}$ & 3.88 \\
\hline 4 & $\begin{array}{l}\text { The integration of the tool to } \\
\text { this course has greatly influ- } \\
\text { enced my time management } \\
\text { skills. }\end{array}$ & $10.0 \%(4)$ & $7.5 \%(3)$ & $5.0 \%(2)$ & $60.0 \%(24)$ & $\begin{array}{l}17.5 \% \\
(7)\end{array}$ & 3.68 \\
\hline 5 & $\begin{array}{l}\text { The tool is an effective mean } \\
\text { of communicating the course } \\
\text { announcements/materials. }\end{array}$ & $5.0 \%(2)$ & $7.5 \%(3)$ & $7.5 \%(3)$ & $45.0 \%(18)$ & $\begin{array}{l}35.0 \% \\
(14)\end{array}$ & 3.98 \\
\hline 6 & $\begin{array}{l}\text { The tool has greatly influenced } \\
\text { my academic performance in } \\
\text { the course. }\end{array}$ & $7.5 \%(3)$ & $7.5 \%(3)$ & $0.0 \%(0)$ & $52.5 \%(21)$ & $\begin{array}{l}32.5 \% \\
(15)\end{array}$ & 3.95 \\
\hline 7 & $\begin{array}{l}\text { The tool is easy, user friendly } \\
\text { and its interface layer well } \\
\text { organized. }\end{array}$ & $0.0 \%(0)$ & $2.5 \%(1)$ & $0.0 \%(0)$ & $22.5 \%(9)$ & $\begin{array}{l}75.0 \% \\
(30)\end{array}$ & 4.70 \\
\hline 8 & $\begin{array}{l}\text { The cost of using the tool is } \\
\text { high }\end{array}$ & $\begin{array}{l}77.5 \% \\
(31)\end{array}$ & $20.0 \%(8)$ & $2.5 \%(1)$ & $\begin{array}{l}0.0 \% \\
(0)\end{array}$ & $0.0 \%(0)$ & 1.25 \\
\hline 9 & $\begin{array}{l}\text { Sending and receiving course } \\
\text { announcement is instantaneous } \\
\text { (perceived response time) }\end{array}$ & $5.0 \%(2)$ & $7.5 \%(3)$ & $2.5 \%(1)$ & $25.0 \%(10)$ & $\begin{array}{l}60.0 \% \\
(24)\end{array}$ & 4.28 \\
\hline 10 & $\begin{array}{l}\text { Additional hardware/software } \\
\text { other than Internet connectivity } \\
\text { and ordinary mobile phones are } \\
\text { needed before I can use the } \\
\text { tool }\end{array}$ & $60.0 \%(24)$ & $25.0 \%(10)$ & $5.0 \%(2)$ & $7.5 \%(3)$ & $2.5 \%(1)$ & 1.68 \\
\hline 11 & $\begin{array}{l}\text { A lot of improvements still } \\
\text { need to be added to enhance } \\
\text { this tool }\end{array}$ & $45.0 \%(18)$ & $37.5 \%(15)$ & $2.5 \%(1)$ & $10.0 \%(4)$ & $5.0 \%(2)$ & 1.93 \\
\hline 12 & $\begin{array}{l}\text { I support the introduction of } \\
\text { the tool to other courses in the } \\
\text { department }\end{array}$ & $2.5 \%(1)$ & $5.0 \%(2)$ & $2.5 \%(1)$ & $27.5 \%(11)$ & $\begin{array}{l}62.5 \% \\
(25)\end{array}$ & 4.43 \\
\hline
\end{tabular}




\section{Conclusion}

It is generally true that technology which supports the learning environment has the potential to enhance learning by encouraging students to actively engage in and shape their personal learning experiences, the system presented in this study is a robust one, with lot of efforts put in its design. The system consists of the mobile and the web modules. The mobile component was designed to be platform independent, which allows the system to run on less expensive mobile phones. The design of the mobile application module took into consideration network failures by incorporating facility, which supports data persistency on mobile phones. The web module, developed with PHP, can easily be installed on any website, even on simple sites with no database technology. This makes the deployment of the system to be possible in virtually all learning environments supporting the basic electronic telecommunications systems.

We hope to integrate the system with the university's e-portal, so it can be accessible to all lecturers and students in the university.

Generally, it is believed that contact as well as support to students from lecturers will improve learning, students' satisfaction, and pass rates (Rau, Gao, \& Wu, 2008). As expected, this technology will help students stay up-to-date on their studies, as well as yield a combination of immediate and long lasting benefits. On the immediate edge is the teaching methods employed to boost students' confidence in their studies. In addition, the increased interaction between students, as well as between students and lecturers, will assist in early identification of students that are problematic.

\section{References}

Ajayi, A. O, Aderounmu, G. A., Soriyan, H. A., \& Amos, D. (2010). An intelligent quality of service brokering model for e-commerce. Expert Systems with Applications, 37(1), 816-823.

Asmus, J., Bonner, C., Esterhay, D., Lechner, A., \& Rentfrow, C. (2005). Instructional design technology trend analysis. Retrieved February 4, 2011 from http://elgg.net/collinb/files/1136/2967/TrendAnalysisWeb.pdf

Collett, M., \& Stead, G. (2002). Meeting the challenge: Producing m-learning materials for young adults with numeracy and literacy needs. Proceedings of the European Workshop on Mobile and Contextual Learning, Birmingham, UK, 61-62.

Corlett, D., Sharples, M., Bull, S., \& Chan, T. (2005). Evaluation of a mobile learning organizer for university students. Journal of Computer Assisted Learning, 21(3), 162-170.

Correia, P., Faria, S. M., Assuncao, P. A. (2001). Matching MPEG-1/2 coded video to mobile applications. 4th International Symposium on Wireless Personal Multimedia Communications, Aalborg - Denmark, 699-704.

Dvorak, J., \& Burchanan, K. (2002). Using technology to create and enhance collaborative learning. Proceedings of 14th World Conference on Educational Multimedia, Hypermedia and Telecommunications, Denver, CO, USA, 459-464.

Garner, I., Francis, J., \& Wales, K. (2002). An evaluation of the implementation of a short messaging system (SMS) to support undergraduate students. Proceedings of the European Workshop on Mobile and Contextual Learning, Birmingham, UK, 15-18.

Gillard, S., Bailey, D., \& Nolan, E. (2008). Ten reasons for IT educators to be early adopters of IT innovations. Journal of Information Technology Education, 7, 21-33. Retrieved from http://www.jite.org/documents/Vol7/JITEv7p021-033Gillard257.pdf

Glotzbach, R., Mordkovich, D., \& Radwan, J. (2008). Syndicated RSS feeds for course information distribution. Journal of Information Technology Education, 7, 163-183. Retrieved from http://www.jite.org/documents/Vol7/JITEv7p163-183Glotzbach293.pdf 
Ismail, I, \& Idrus, R. M. (2009). Development of SMS mobile technology for m-learning for distance learners. International Journal of Interactive Mobile Technologies, 3(2), 55-57.

Jones, V., Jo, J. H., \& Cranitch, G. (2002). HyWeb: A holistic approach to technology-based tertiary education. Proceedings of 14th World Conference on Educational Multimedia, Hypermedia and Telecommunications, Denver, CO, USA, 896-897.

Kim, S., Mims, C., \& Holmes, K. (2006). An introduction to current trends and benefits of mobile wireless technology use in higher education. Association for the Advancement of Computing in Education Journal, 14(1), 77-100.

Lehner, F., Nosekabel, H., \& Lehmann, H. (2002). Wireless e-learning and communication environment: Welcome at the University of Regensburg. e-Service Journal, 2(3), 23-41.

McKenzie, J. (2001). The unwired classroom: Wireless computers come of age. Educational Technology, 10(4). Retrieved October 6, 2010, from http://www.fno.org/jan01/wireless.html

Nyiri, K. (2002). Towards a philosophy of M-Learning. Proceedings of the IEEE International Workshop on Wireless and Mobile Technologies in Education Växjö, Sweden, 121-124.

Oliver, B. (2005). Australian university students' use of and altitudes towards mobile learning and technologies. Proceedings of the IADIS international conference on mobile learning, Qawra,, Malta, 193197.Retrieved from http://www.iadis.net/dl/final_uploads/200506C004.pdf

Rau, P. L., Gao, Q., \& Wu., L. M. (2008). Using mobile communication in high school education: Motivation, pressure and learning performance. Computers and Education, 50(1), 1-22.

Seppälä, P. (2002). Mobile learning and mobility in teacher training. Proceedings of IEEE International Workshop on Wireless and Mobile Technologies in Education, Växjö, Sweden, 130-135.

Smørdal, O., Gregory, J., \& Langseth, K. (2002). PDAs in medical education and practice. Proceedings of IEEE International Workshop on Wireless and Mobile Technologies in Education, Växjö, Sweden, 140-146.

Stone, A., \& Briggs, J. (2002). ITZ GD 2 TXT - How to use SMS effectively in m-learning. Proceedings of the European Workshop on Mobile and Contextual Learning, Birmingham, UK, 11-14.

Tong, R., Hu, Z., Han, P., \& Yang, F. (2005). A novel mobile learning assistant system. Lecture Notes in Computer Science, 3583, 340-348.

Virtanen, V., John, S., \& Wright, K. (2002). Nokia and Midwest Wireless establish model wireless campus at Minnesota State University. Nokia press release, available online at http://press.nokia.com/PR/200009/790728_5.html

Virvou, M., \& Alepis, E. (2005). Mobile educational features in authoring tools for personalized tutoring, Computers and Education, 44(1), 53-68.

Waycott, J. (2002). An investigation into the use of mobile computing devices as tools for supporting learning and workplace activities. 5th Human Centred Technology Postgraduate Workshop, Brighton, UK, available online at http://www.cogs.susx.ac.uk/lab/hct/hctw2001/papers/waycott.pdf

\section{Biographies}

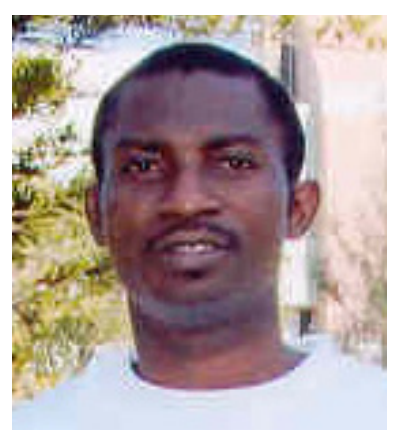

Anuoluwapo Ajayi received Ph.D. degree in Computer Science from the Obafemi Awolowo University (OAU), Ile-Ife, Nigeria. He is a lecturer in the Department of Computer Science and Engineering, OAU, Ile-Ife. His research interests include artificial intelligence and information systems. He is a member of International Association of Engineers (IAENG), Nigerian Computer Society (NCS) and IEEE Computer society. He has published in journals and learned conferences. 


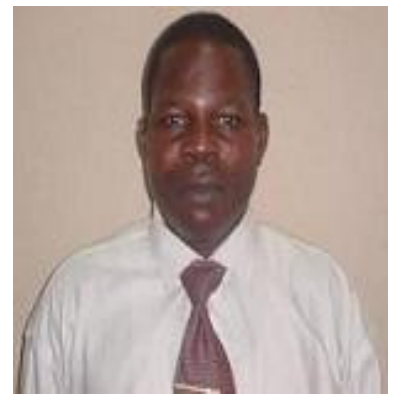

Emmanuel Olajubu received $\mathrm{Ph} . \mathrm{D}$. degree in Computer Science from the Obafemi Awolowo University (OAU), Ile-Ife, Nigeria. He is a member of Nigerian Computer Society, Computer Professional Registration Council of Nigeria, and International Association of Engineers (IAENG). He has over 11 years of experience in teaching and research. He has published in reputable journals and learned conferences. His research interests include computer communications and intelligent systems.

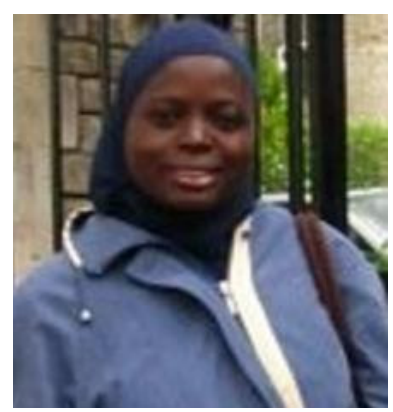

Sururah Bello obtained B.Sc. Computer Engineering, M.Sc. and $\mathrm{Ph}$.D. degrees in Computer Science from the Obafemi Awolowo University (OAU), Ile-Ife. She is a lecturer in the Department of Computer Science and Engineering, OAU, Ile-Ife. Her research interests include curriculum issues in engineering education and grid computing. She is a member of the Nigerian Computer Society (NCS) and a registered Computer Engineer with Council for the Regulation of Engineering Practise in Nigeria (COREN).

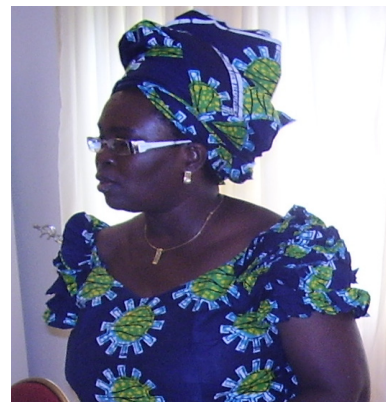

Abimbola Soriyan (Ph.D. Obafemi Awolowo University) is the current Deputy Director, Distance Learning Center, Obafemi Awolowo University, Ile-Ife, Nigeria. She has over 19 years of experience in teaching and research. Her interests include information systems development with emphasis on healthcare. She has published a good number of journal and learned conference articles, and made useful contributions to books.

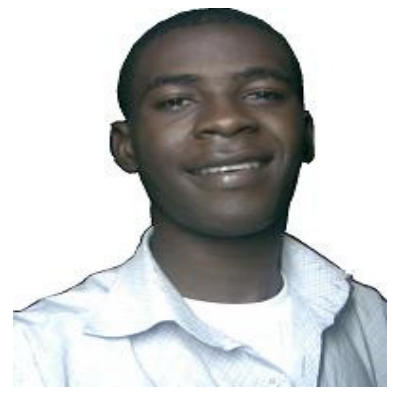

Abiola Obamuyide obtained B.Sc. (Hons) degree, First Class Division, in Computer Science with Economics, from the Obafemi Awolowo University, Ile-Ife, Nigeria. He is a recipient of several undergraduate scholarships. His research interests include information systems development, software management, and information retrieval. 